Neurosurg Focus 11 (2):Article 4, 2001, Click here to return to Table of Contents

\title{
A brief history of aneurysm clips
}

\author{
Deon F. Louw, M.D., Wilson T. Asfora, M.D., and Garnette R. Sutherland, M.D. \\ Sioux Valley Hospital, and Department of Surgery, University of South Dakota, Sioux Falls; \\ Department of Clinical Neurosciences, Division of Neurosurgery, The Seaman Family MR Research \\ Centre, University of Calgary, Alberta, Canada
}

\begin{abstract}
In this communication the authors outline the development of aneurysm clips from those originally used by Walter Dandy to those currently in use. The history is rich in contributions from neurosurgical pioneers and innovators. As a result, the modern neurosurgeon has a wide selection of biocompatible aneurysm clips with known closing pressure, of variable sizes and shapes, and a selection of clip applicators that do not obstruct the surgical field.
\end{abstract}

KEY WORDS - cerebral aneurysm • aneurysm clip • neurosurgical history

The history of aneurysm surgery is a triumph of tenacity and skill over a lethal and cryptic disease. Many luminaries thought the effort futile; Harvey Cushing, in fact, commented that the intracranial aneurysm was "a lesion having such remote surgical bearings... whether there are surgical indications such as ligation of the internal carotid, further experience alone can tell. , $^{3,10}$

The initial approach to intracranial aneurysm surgery was based on the Hunterian principle of proximal ligation of the feeding artery, inducing thrombosis within the aneurysm. Victor Horsley first accomplished this in 1885 by occluding the cervical carotid artery to treat an ipsilateral intracranial aneurysm. ${ }^{12}$ In 1931, Dott $^{6}$ developed the technique of reinforcing the wall of the aneurysm by packing muscle around the sac. The indirect method of trapping the aneurysm was introduced by Dandy in 1942. These "passive" strategies, however, had a high failure rate, and courageous surgeons concluded that aneurysms needed to be directly attacked. This manuscript is a brief account of their adventurous efforts.

\section{PIONEERING ERA IN ANEURYSM SURGERY}

The modern goal of intracranial aneurysm surgery is to isolate the thin-walled aneurysm from arterial flow while maintaining the normal patency of the parent artery and adjacent branches. On March 23, 1937, Walter Dandy was the first person to accomplish this by applying a V-shaped, malleable silver clip to the neck of an internal carotid artery aneurysm. ${ }^{4}$ Dandy's report is a fascinating account of a 43-year-old alcoholic man with a painful right third cranial nerve palsy. A diagnosis of "aneurysm along the circle of Willis" was contemplated. The patient underwent

Abbreviation used in this paper: $\mathrm{MR}=$ magnetic resonance. a "hypophyseal" approach, and surgery was facilitated by marked cortical atrophy. Dandy noted that "the small neck of the aneurysm afforded an easy surgical attack," and he proceeded to obliterate it completely by using a flat clip. The patient did well, with rapid resolution of the third nerve palsy. What is astonishing about this accomplishment is that angiography was not used, despite its development by Moniz ${ }^{17}$ in $1927 . .^{13}$

Herbert Olivecrona modified the malleable silver clip by adding winged blades, an innovation that allowed the clip to be reopened if placement was suboptimal. ${ }^{18}$ These clips, however, could crush the aneurysm neck and cause shearing and tearing. To overcome these limitations, Schwartz introduced miniaturized spring forceps as clips. ${ }^{15}$ McFadden,,${ }^{16}$ in his scholarly treatise on the origins of spring forceps, pointed out that they were invented in 1840 by the French instrument maker Joseph Charriere. His strategy of crossing the legs of the forceps was the most important alteration of the basic forceps mechanism since its invention in prehistoric times. ${ }^{16}$ This reversed the action of the forceps, opening when compressed and closing when released, and created a self-closing and selfholding clamp that could be applied and removed with one hand. ${ }^{16}$ Schwartz' clip was designed as a temporary device but, in the absence of alternatives, was placed permanently in many patients. The clip was large and the applicator awkward, leading Mayfield to make modifications in $1952 .{ }^{15} \mathrm{He}$ and Kees, an engineer, slimmed the size of the shank as much as possible and produced clips of variable length, from 6 to $15 \mathrm{~mm}$. Various combinations of forward- and lateral-moving angles to the blades were created. Serrations could be added to the blades to increase purchase and reduce the risk of slipping. Mayfield chose stainless steel 301, believing that it was malleable while retaining adequate spring recoil. Interest- 
ingly, at that time he managed to persuade seven human volunteers to undergo surgical exposure of their temporal arteries and to have them temporarily clipped. Fortunately, they concluded that risk of delayed thrombosis was "extremely low."15 Mayfield and Kees also designed a clip applicator with tweezerlike dexterity and a drop lock. ${ }^{15}$

In the following decades substantial modifications to the basic Mayfield clip were introduced as various neurosurgeons suggested improvements. The Drake clip incorporated an aperture in the blades, preserving arteries or nerves adjacent to the aneurysm neck. Fox ${ }^{9}$ described how Drake's clip was made overnight by Kees, just in time for him to treat surgically a basilar artery aneurysm and still protect the posterior cerebral artery. Del Maestro's account $^{5}$ of the history of the fenestrated clip indicates that it followed the aphorism "Nihil simul inventum est et perfectum (Nothing is invented and perfected at the same time)." Alexander noted that the cross legs of clips could act as scissors and sever vessels, prompting Mayfield to separate the legs to prevent this complication. ${ }^{15}$ Chaffee $^{1}$ bent the straight tips of Mayfield's clip, allowing their tapered and overlapping tips to bypass each other and reduce risk of slippage.

The modification introduced by McFadden ${ }^{15}$ was to create round instead of flat blades and to blunt their tips. The Lougheed-Kerr spring clip was an unusual variation, in which an attached ring provided the spring action of the clip. The ring could be placed through different apertures in the clip base, altering its closing force. The clip could also be rotated in any direction in the clip holder. ${ }^{9,14}$ Scoville's innovation ${ }^{19}$ was to place a coiled spring with an axis parallel to the plane of clip closure. ${ }^{9}$ Heifetz $^{11}$ designed a clip with an internal, nonfatiguing wire spring to close the clip, in which the jaws were slightly rounded and serrated..$^{9}$ An important advance was made by George Smith, who used a vessel-encircling clip to attack aneurysms on the arterial wall opposite the surgeon. ${ }^{9}$ Sundt and Nofzinger $^{22}$ expanded on this notion by developing a Teflon-lined, encircling clip-graft. Their clip could be used in emergency situations to reconstruct torn vessels. Selected clips from the pioneering era are presented in Fig. 1.

\section{MODERN ERA IN ANEURYSM SURGERY}

Routine use of the microscope placed new demands on the design of aneurysm clips, particularly because surgeons had to navigate increasingly narrow and deep surgical corridors. Yaşargil, et al., ${ }^{25}$ therefore developed a cross-action spring clip with strong closing pressures and a narrow base, which increased one's visibility of the aneurysm neck. Sugita, et al., ${ }^{21}$ created very long clips, up to $4 \mathrm{~cm}$, which were used effectively to treat giant and deeply located aneurysms. ${ }^{24}$ They also developed bayonet clips and applicators, minimizing visual obstruction in the operative field. Interestingly many of their creations were based on Drake's ideas, gleaned from a visit to London. ${ }^{5}$ Unfortunately, Drake could not persuade Kees to modify the clip angles and lengths, as the latter believed this would be too expensive. Sugita returned to Japan and began manufacturing modifications to the Drake clip, which "turned out to be a best seller," according to Drake. ${ }^{5}$ The design of aneurysm clips also had to become compatible with magnets once MR imaging was introduced; many companies made titanium clips. Few are aware that Steiner devised the first titanium clip, albeit to reduce artifacts computerized tomography scanning. ${ }^{23}$ The Spetzler clip is a good example of one that underwent rigorous testing of MR imaging compatibility and demonstrated an adequate safety profile. ${ }^{20}$ The Spetzler clip is made of commercially pure titanium and has been proven safe at 4.3 tesla. Because the blades have DeBakey-style interlocking sinusoidal grooves, the contact area on the aneurysm neck is increased and slippage is reduced. They are so-called "smart clips" with metallic memory capabilities. It is apparent that a veritable catalog of clips has been created over the years, including temporary, "piggyback," perforated clips to hold sutures and splayed tips to reduce risk of aneurysm perforation..$^{2,8}$

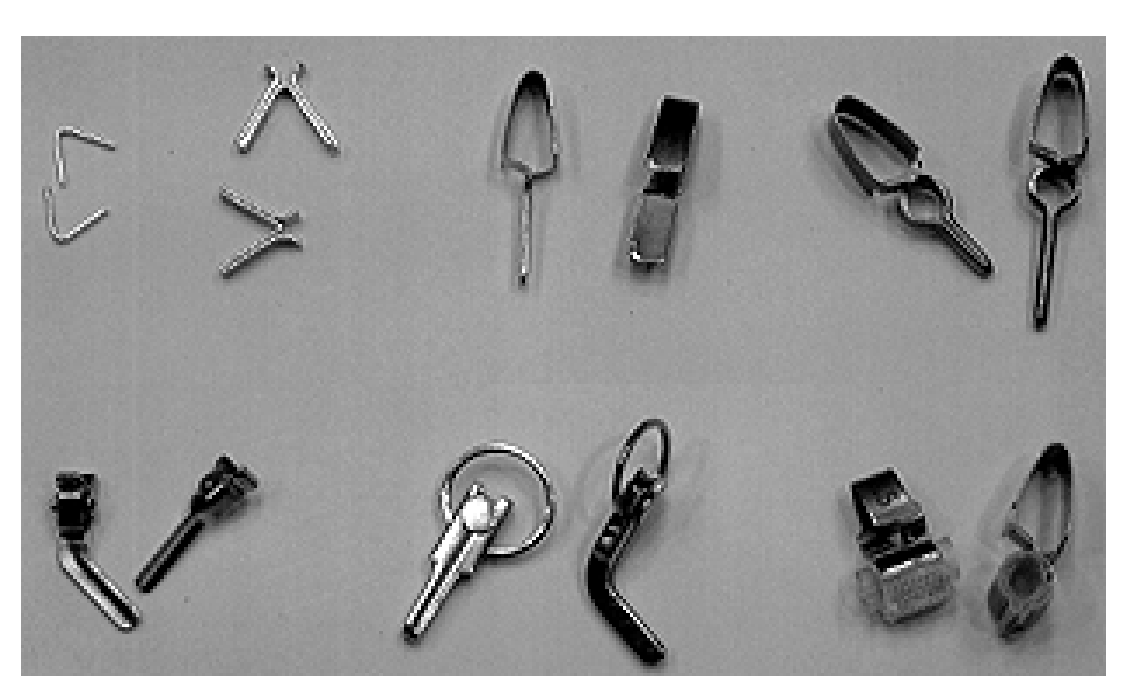

Fig. 1. Photograph showing selected paired aneurysm clips produced during the pioneering era of aneursym surgery. Clockwise from upper left: the V-shaped clips, originally used in 1937 by Dandy; Olivecrona clips; Mayfield clips; Drake clips; Heifetz clips; Lougheed-Kerr clips; and Sundt clips. 
Unfortunately, the development of aneurysm clips is a tale not merely of triumph but one of tragedy. Dujovny, et al., ${ }^{7}$ noted that many of these previous experiences with aneurysm surgery were conducted using clips of unknown biocompatibility and metallurgic patterns. Manufacturers lacked quality-control procedures for clip closing pressures as well, and remarkably one even recommended that the clip undergo assessment by applying it to the skin of the thumb. This supposedly generated pain proportional to closing pressure. Hence, corrosion of clips caused catastrophic hemorrhage in a few patients, and a patient in whom an incompatible clip had been placed died during an MR imaging session. ${ }^{7}$ In response, the American Society for Testing and Materials Committee developed strict guidelines for brain clip biocompatibility and measurement of clip closing forces. The committee advocated stringent biomagnetic compatibility. Manufacturers using nonapproved materials had to do so at their own risk, and several clip types disappeared from the marketplace. ${ }^{7}$ To improve quality, many manufacturers of aneurysm clips required that dedicated workers produce a specific clip type and length only. Figure 2 left displays a selection of clips used in the modern era of aneurysm surgery and Fig. 2 right shows the single Olivecrona clip applicator in contrast to the selection of applicators available for the Yaşargil, or Aesculap clips.

It is tempting to speculate on the direction of aneurysm clip design. Perhaps we may create "intelligent" clips that have sensors in their tips, preventing perforating injury to distal structures. More advanced pre- and intraoperative imaging modalities would improve three-dimensional characterization of aneurysm anatomy, optimizing clip selection. Combined with novel technology, this could allow the rapid manufacture of "designer" clips that would be tailored to each patient's angioarchitecture. Nanotechnology would allow development of robust, light, and highly biocompatible materials that could be used to construct new clips. Aneurysm clip applicators would consequently change and could be made in a variety of different shapes to minimize obstruction of the surgical field. These futuristic clips could be married to robotic technology. Modern robots are already capable of movements with submillimetric accuracy, and miniature optical force/strain sensors can detect changes as low as $10 \mathrm{mN}$. Such advances will become increasingly important as endovascular intervention eliminates the simpler aneurysms from the surgeon's palette.

\section{References}

1. Chaffee BA: Modified aneurysm clip. J Neurosurg 26:449, 1967

2. Cuatico W: A suggested design for tips of aneurysmal clips: a new concept. Neurosurgery 36:615-616, 1995

3. Cushing H: Contributions to the study of intracranial aneurysms. Guys Hosp Rep 73:159-163, 1923

4. Dandy WE: Intracranial aneurysm of internal carotid artery cured by operation. Ann Surg 107:654, 1938

5. Del Maestro RF: Origin of the Drake fenestrated aneurysm clip. J Neurosurg 92:1056-1064, 2000

6. Dott NM: Intracranial aneurysms: cerebral arteriography: surgical treatment. Edinburgh Med J 40:219, 1933

7. Dujovny M, Dujovny N, Slavin KV: Aneurysm clips: twenty years later. Neurol Res 16:4-5, 1994

8. Feild JR: Suturing the aneurysm clip to the aneurysm sac. Perforated aneurysm clips: a technical note. Surg Neurol 27: 501-502, 1987

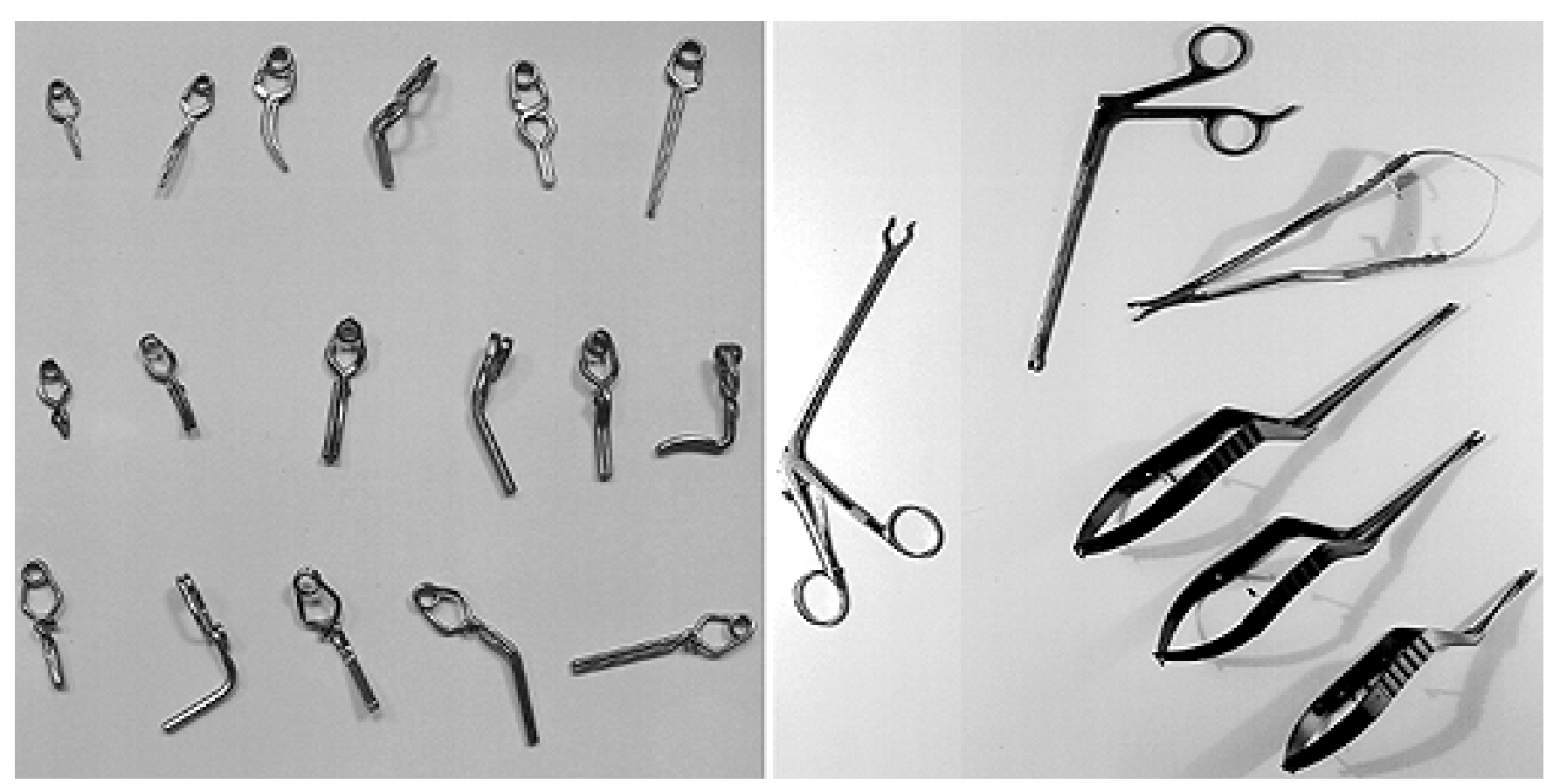

Fig. 2. Photographs. Left: Selected MR-compatible aneurysm clips manufactured during the modern era. Upper Row: Yaşargil clips. Center Row: Sugita clips. Lower Row: Spetzler clips. Right: Comparison of the single Olivecrona clip applicator (left) with a selection of Yaşargil clip applicator available for modern clip application (right). 


\section{F. Louw, W. T. Asfora, and G. R. Sutherland}

9. Fox JL: Vascular clips for the microsurgical treatment of stroke. Stroke 7:489-500, 1976

10. Fox JL (ed): Intracranial Aneurysms. New York: SpringerVerlag, 1983, Vol 1-7

11. Heifetz MD: A new intracranial aneurysm clip. J Neurosurg 30:753, 1969

12. Keen WW: Intracranial lesions. Med News 57:443, 1890

13. Lee S, Marroti L, Awad IA: A history of cerebrovascular surgery, in Barrow DL, Kondziolka D, Laws ER, et al (eds): Fifty Years of Neurosurgery. Philadelphia: Lippincott Williams \& Wilkins, 2000, pp 143-168

14. Lougheed WM, Khodadad G: A new clip for surgery of intracranial and small blood vessels. J Neurosurg 22:397-398, 1965

15. Mayfield FH, Kees G Jr: A brief history of the development of the Mayfield clip. Technical note. J Neurosurg 35:97-100, 1971

16. McFadden JT: The origin and evolutionary principles of spring forceps. Surg Gynecol Obstet 130:356-368, 1970

17. Moniz E: L'encéphalographie artérielle, son importance dans la localization des tumeurs cerebrales. Rev Neurol 2:72, 1927

18. Norlén G, Olivecrona $\mathrm{H}$ : The treatment of aneurysms of the circle of Willis. J Neurosurg 10:404-415, 1953

19. Scoville WB: Miniature torsion bar spring aneurysm clip. J Neurosurg 25:97, 1966
20. Shellock FG, Shellock VJ: Spetzler titanium aneurysm clips: compatibility at MR imaging. Radiology 206:838-841, 1998

21. Sugita K, Kobayashi S, Inoue T, et al: Characteristics and use of ultra-long aneurysm clips. J Neurosurg 60:145-150, 1984

22. Sundt TM, Nofzinger JD: Clip-grafts for aneurysm and small vessel surgery. Part 1 . Repair of segmental defects with clipgrafts: laboratory studies and clinical correlations. Part 2. Clinical application of clip-grafts to aneurysms: technical considerations. J Neurosurg 27:477-489, 1967

23. von Holst H, Bergstrom M, Moller A, et al: Titanium clips in neurosurgery for elimination of artefacts in computer tomography (ct): a technical note. Acta Neurochir 38:101-109, 1977

24. Weir B: Aneurysms Affecting the Nervous System. Baltimore: Williams \& Wilkins, 1987, p 431

25. Yaşargil MG, Vise WM, Bader DC: Technical adjuncts in neurosurgery. Surg Neurol 8:331-336, 1977

Manuscript received June 13, 2001.

Accepted in final form July 24, 2001.

This work was supported from a grant from the Canadian Foundation for Innovation (to Garnette Sutherland).

Address reprint requests to: Deon F. Louw, M.D., F.R.C.S.(C), Sioux Valley Hospital, Medical Building 3, 1500 West 22nd Street, Suite 101, Sioux Falls, South Dakota, 57105. email: research@ asforana.com. 